\title{
Synthetic human secretin did not improve symptoms or communication skills in children with autistic disorders
}

Sandler AD, Sutton KA, DeWeese J, et al. Lack of benefit of a single dose of synthetic human secretin in the treatment of autism and pervasive developmental disorder. $N$ Engl J Med 1999 Dec 9;341:1801-6.

QUESTION: In children with autistic disorders, is synthetic human secretin effective for improving symptoms and communication skills?

\section{Design}

Randomised \{allocation concealed*\}†, blinded (patients, clinicians, outcome assessors),* placebo controlled trial with 4 weeks of follow up.

Setting

A university in Chapel Hill, North Carolina, USA.

\section{Patients}

60 children who were $3-14$ years of age (mean age 8 y) and had a previous diagnosis of autism were screened by using the $D S M-I V$, the Childhood Autism Rating Scale, and the Autism Behavior Checklist (ABC). 40 children met criteria for autism, and 20 met criteria for another pervasive developmental disorder. Exclusion criteria were previous secretin treatment; or diagnosis of pancreatitis, inflammatory bowel disease, or gastrinoma. Follow up was $87 \%$ for treatment response.

\section{Intervention}

After stratification for age, children were allocated to a single infusion of secretin, $0.4 \mu \mathrm{g} / \mathrm{kg}$ of body weight $(\mathrm{n}=30)$, or placebo $(\mathrm{n}=30)$ by slow intravenous injection over 1 minute.

\section{Main outcome measures}

Communication skills (subscale of the Vineland Adaptive Behavior Scales completed by clinicians), autistic symptoms (ABC and Clinical Global Impression Scale [CGI] completed by parents), and adverse effects (Treatment Emergent Symptoms Scale completed by clinicians). Response to treatment was defined as a "much" or "very much" improved score on any of the 8 measures of the CGI.

Sources of funding:

Thoms Health Services

Foundation and

National Institute of

Child Health and

Human Development.

For correspondence: $\mathrm{Dr}$ A D Sandler, Olson

Huff Center for Child

Development, Thoms

Rehabilitation

Hospital, 68 Sweeten

Creek Road, Asheville,

NC 28803, USA. Fax

+18282774831 .

\section{Main results}

The groups did not differ for treatment response $(\mathrm{p}=0.68) \quad$ (table). No differences existed between groups for any outcome. Children in both groups reported an improvement in symptoms from baseline for the $\mathrm{ABC}$ total score $(\mathrm{p}<0.001)$, $\mathrm{ABC}$ sensoryfunction score $(\mathrm{p}<0.001)$, ABC social relatedness score $(\mathrm{p}<0.001)$, ABC language score $(\mathrm{p}=0.05), \mathrm{ABC}$ socialisation score $(\mathrm{p}<0.001)$, and CGI speech score $(p=0.02)$. No child had adverse effects that limited treatment.

Synthetic human secretin v placebo for autistic disorders in children $\neq$

\begin{tabular}{ccccc} 
Outcome at 4 wks & Secretin & Placebo & RBI (95\% Cl) & NNT \\
Treatment response & $33 \%$ & $28 \%$ & $19 \%(-47$ to 171$)$ & Not significant \\
\hline †Abbreviations defined in glossary; $\mathrm{RBI}, \mathrm{NNT}$, and $\mathrm{Cl}$ calculated from data in article.
\end{tabular}

\section{Conclusion}

In children with autism or another pervasive developmental disorder, synthetic human secretin did not improve symptoms or communication skills more than did placebo.

*See glossary.

$\dagger$ Information supplied by author.

\section{COMMENTARY}

The report by Sandler et al on treating symptoms of autistic spectrum disorders with the synthetic peptide hormone secretin has shown a complete lack of efficacy, with equal rates of parent reported improvement for both secretin and placebo in a double blind study with 4 weeks of follow up after a single infusion.

The findings are not surprising given the impetus for the study: a mother noted behavioural improvements anecdotally in her self described autistic child after secretin infusion. This improvement was subsequently reported as a reasonable causal occurrence, appearing in testimonial form on the internet (eg, http://www.feat.org). Subsequently, the same case was reported on a primetime US television news magazine (NBC Dateline) and received further credibility by being published on the front page of the Wall Street Journal. One medical journal published a report of 3 open label cases (including the child reported by Wall Street Journal and Dateline) and also claimed success. ${ }^{2}$ Opinion formulated from these sources blurred the line between scientific reporting, journalism, and hearsay. Nevertheless, demand for the treatment skyrocketed. The National Institutes of Health supported treatment trials, although the usually required scientific bases, such as convincing pilot data or sound theory, were lacking. All this creates a danger zone where opinion dictates treatment, research agenda, the spending of precious research dollars, and the efforts of highly trained investigators.

Autism is a debilitating and lifelong disorder. Children with autism, however, look "normal". Parents who struggle to help their child may believe that the "hoped for" child exists-a homunculus inside the child with autism-but is held prisoner by a web of abnormal behavioural patterns. These conditions may be hazardous to generalist clinicians who, when prevailed upon to give secretin, may not know that secretin is likely to produce only the latest placebo effect seen in a long line of nominally plausible treatments for autism. ${ }^{3}$

Bryna Siegel, $\mathrm{PhD}$ University of California, San Francisco San Francisco, California, USA

1 Johannes L. Solitary crusade: mother's quest to help treat autism advances after some odd turns. Wall Street Journal 1999 Mar 10;Sect.A:1.

2 Horvath K, Stefanatos G, Sokolski KN, et al. Improved social and language skills after secretin administration in patients with autistic spectrum disorders. J Assoc Acad Minor Phys 1998;9:9-15.

3 Volkmar FR. Lessons from secretin. $N$ Engl $J$ Med 1999;341:1842-4. 